\title{
99\% Efficient Three-Phase Buck-Type SiC MOSFET PFC Rectifier Minimizing Life Cycle Cost in DC Data Centers
}

\author{
Lukas Schrittwieser, Johann W. Kolar, and Thiago Batista Soeiro
}

\begin{abstract}
Due to the increasing power consumption of data centers, efficient dc power distribution systems have become an important topic in research and industry over the last years and according standards have been adopted. Furthermore the power consumed by telecommunication equipment and data centers is an economic factor for the equipment operator, which implies that all parts of the distribution system should be designed to minimize the life cycle cost, i.e. the sum of first cost and the cost of the power conversion losses. This paper demonstrates how semiconductor technology, chip area, magnetic component volumes and switching frequency can be selected based on life cycle cost, using analytical and numerical optimizations. A three-phase buck-type PFC rectifier with integrated active filter for $380 \mathrm{~V}$ dc distribution systems is used as an example system, which shows that a peak efficiency of $\mathbf{9 9 \%}$ is technically and economically feasible with state-of-the-art SiC MOSFETs and nanocrystalline or ferrite cores. Measurements taken on an $8 \mathrm{~kW}, 4 \mathrm{kWdm}^{-3}$ hardware prototype demonstrate the validity and feasibility of the design.
\end{abstract}

Index Terms-Active third-harmonic current injection, bucktype power factor correction (PFC) converter, three-phase rectifier systems, integrated active filter rectifier.

\section{INTRODUCTION}

$I^{N}$ NFORMATION and communication technology equipment has become a significant consumer of electric power in recent years. In 2007, for example, the related annual consumption in Germany alone was 55TWh which equaled approximately $10 \%$ of the countries total consumption. The annual power consumption of data centers located in Germany is approximately constant at $\approx 10 \mathrm{TWh}$ since 2008 [1]. For the US an annual data center power consumption of $60 \mathrm{TWh}$ was estimated in 2006 with a energy cost of $\$ 4.5$ billion [2], for 2014 an increase to 70TWh has been reported [3]. Therefore the cost of electric energy is a significant economic factor for data center operators and should hence be considered in investment decisions.

In conventional data centers using ac distribution systems, as shown in Fig. 1(a), up to $50 \%$ of the total energy con-

Manuscript received March 27, 2017.

Lukas Schrittwieser, and Johann W. Kolar are with Power Electronic Systems Laboratory, ETH Zurich, Switzerland, Thiago Batista Soeiro is with ABB Switzerland Ltd., Corporate Research, 5405 Baden-Dättwil, Switzerland (e-mail: schritt-wieser@lem.ee.ethz.ch).

Digital Object Identifier 10.24295/CPSSTPEA.2017.00006

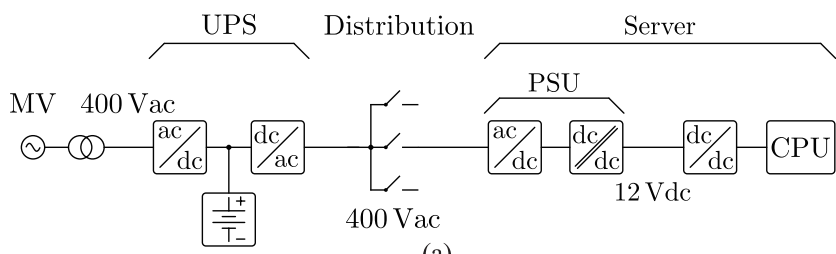

(a)

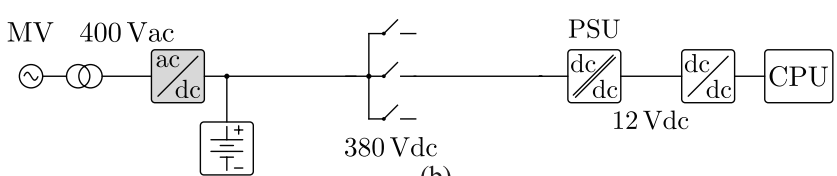

(b)

Fig. 1. Data center power distribution concepts: (a) Conventional 400 Vac distribution, using an ac output Uninterruptible Power Supply (UPS). Similar concepts can be used with 480 Vac. (b) Facility level dc distribution system based on a $380 \mathrm{Vdc}$ bus which allows a direct connection of backup batteries [4].

sumed is used for air conditioning, distribution and conversion losses [4]. Compared to this, distribution systems based on a dc bus with a nominal voltage of $380 \mathrm{~V}$ offer significantly higher efficiency, improved reliability and reduced capital cost and floor space, cf. Fig. 1(b) [5]. Furthermore they allow a direct connection of lead acid batteries, consisting of 168 cells connected in series, with a typical floating cell voltage of $\approx 2.26 \mathrm{~V}$, which results in a nominal bus voltage of $380 \mathrm{~V}$. Accordingly, standards and components for de distribution systems have been developed in recent years [6], [7].

Normally a boost-type power factor correction (PFC) stage is used to convert the 400 Vac mains into a dc voltage which is higher than the full-wave rectified ac input voltage, typically in the range of $700 \mathrm{~V}$ to $800 \mathrm{~V}$. A subsequent buck converter is then required to connect the PFC output to the $\mathrm{dc}$ distribution bus. (This configuration is also used for fast chargers of Electric Vehicle batteries which are powered from the three-phase ac mains [8].) As an alternative, a single-stage conversion between the three-phase mains and a dc bus with lower voltage can be achieved with buck-type PFC converters, like the SWISS Rectifier, the six-switch buck rectifier or the Integrated Active Filter rectifier [9]-[12].

The circuit topology of the Integrated Active Filter (IAF) buck-type PFC rectifier, shown in Fig. 2, was first introduced in [13] for three-phase solar inverters. A similar circuit was also proposed for drive systems with small dc-link capacitors [14]. Three major blocks can be identified in the IAF rectifier's schematic: an Input Voltage Selector (IVS) built of 
a linecommutated full-wave diode rectifier $\mathrm{D}_{\overline{\mathrm{kx}}}, \mathrm{D}_{\overline{\mathrm{k}} \mathrm{k}} \overline{\mathrm{k}} \in\{\overline{\mathrm{a}}$, $\overline{\mathrm{b}}, \overline{\mathrm{c}}\} 2$ and three four-quadrant switches $\mathrm{S}_{\overline{\mathrm{kyk}}}$, a current injection circuit $\mathrm{S}_{\mathrm{xy}}, \mathrm{S}_{\mathrm{yz}}, L_{\mathrm{inj}}$ and a dc-dc buck converter $\mathrm{S}_{\mathrm{x}}, \mathrm{D}_{z}, \mathrm{~L}_{\mathrm{o}}$ which provides the constant dc output voltage $u_{\mathrm{pn}}$. Typically a small capacitor $C_{\mathrm{f}}$ is required to ensure a valid conduction path during the commutation of $\mathrm{S}_{\mathrm{xy}}, \mathrm{S}_{\mathrm{yz}}$ and $\mathrm{S}_{\mathrm{x}}$. Note that the IVS switches and diodes are commutated at mains frequency only which implies that almost no switching losses occur in the IVS, therefore rectifier diodes $\mathrm{D}_{\overline{\mathrm{k}} \mathrm{c}}, \mathrm{D}_{\overline{\mathrm{k}} \mathrm{k}}$ which are optimized for a low forward voltage drop can be used.

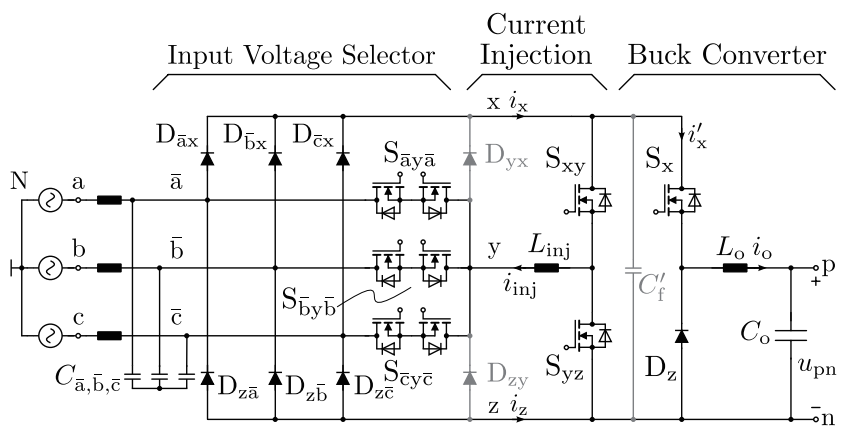

Fig. 2. Schematic of the Integrated Active Filter rectifier (IAF), using an Input Voltage Selector (IVS) commutated at mains frequency, combined with a buck converter providing the output current $i_{o}$ and a current injection converter which serves as active harmonic filter for achieving sinusoidal ac input currents.

For this paper the IAF buck-type PFC rectifier was selected to demonstrate a cost-driven converter design approach, as only two line-commutated diodes $\mathrm{D}_{\overline{\mathrm{k}} \mathrm{x}}, \mathrm{D}_{\overline{\mathrm{k}} \mathrm{k}}$, and one power transistor $\mathrm{S}_{\mathrm{x}}$ are in its main conduction path [9], [15]. Based on a short review of the IAF rectifier's main properties in Section II and using the capital equivalent worth of energy together with component cost models, a non-isolated $8 \mathrm{~kW}$ $\mathrm{PFC}$ rectifier is designed in Section III. This allows selecting cost optimal components such as semiconductors and inductors achieving an economically optimal converter which minimizes life cycle cost, i.e. the sum of first cost of the converter hardware and the cost of conversion losses during the service life. Measurements taken on a hardware prototype are presented in Section IV.

\section{Integrated Active Filter PFC Rectifier}

Simulation results for a $8 \mathrm{~kW}$ IAF buck-type PFC rectifier (cf. Fig. 2) are shown in Fig. 3, for the system specifications given in Table I. For the IAF rectifier the current injection circuit and the buck converter can be analyzed, optimized and operated almost independently of each other. As the dc output is provided by the buck converter $\left(\mathrm{S}_{\mathrm{x}}, \mathrm{D}_{z}, \mathrm{~L}_{\mathrm{o}}\right)$, the output current $i_{o}$ and voltage $u_{\mathrm{pn}}$ can be controlled independently of the injection circuit. This can be seen from the simulation results in Fig. 3: During $\omega t<180^{\circ}$ the current injection circuit is turned off, i.e. $i_{\mathrm{inj}}=0$. As the buck converter creates a constant output current $i_{o}$ it consumes constant power from the ac input. Hence non-sinusoidal ac input currents $i_{\mathrm{a}, \mathrm{b}, \mathrm{c}}$ result and only two ac input phases $i_{\mathrm{a}, \mathrm{b}, \mathrm{c}}$ conduct current at a time.
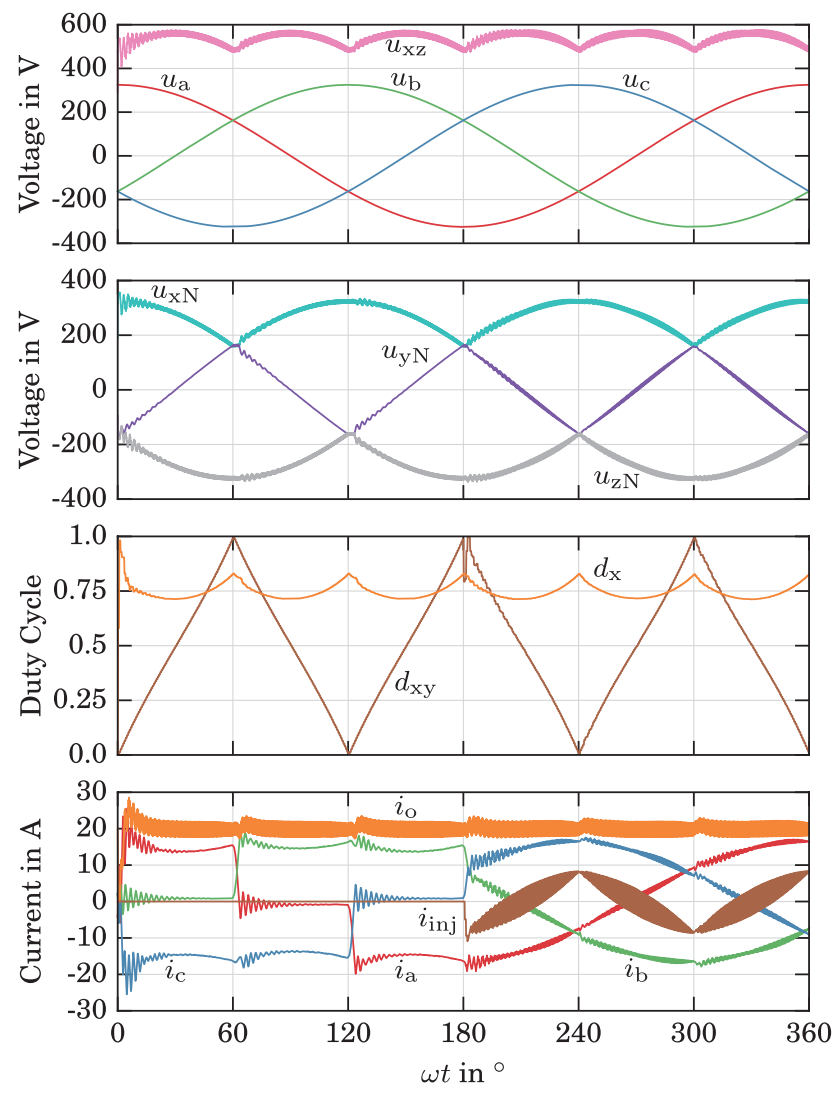

Fig. 3. Simulation results for an IAF buck-type PFC rectifier as shown in Fig. 2, plotted are the ac input voltages $u_{\mathrm{a}, \mathrm{b}}$, , the IVS output voltages $u_{\mathrm{xN}}$, $u_{\mathrm{yN}}$ and $u_{\mathrm{zN}}$, the buck stage duty cycle $d_{\mathrm{x}}$, the duty cycle $d_{\mathrm{xy}}$ of switch $\mathrm{S}_{\mathrm{xy}}$, the output current $i_{0}$, the injection current $i_{\text {inj }}$ and the ac input currents $i_{\mathrm{a}, \mathrm{b}, \mathrm{c} \text {. }}$. During $\omega t<180^{\circ}$ the injection circuit is disabled (i.e. $i_{\text {inj }}=0$ ) which results in non-sinusoidal mains currents $i_{\mathrm{a}, \mathrm{b}, \mathrm{c}}$,

TABLE I

Converter Specifications

\begin{tabular}{ll}
\hline \hline Input Voltage (Line-to-Neutral) & $U_{1}=230 \mathrm{~V} \mathrm{rms}$ \\
Input Frequency & $\omega_{1}=2 \pi 50 \mathrm{~Hz}$ \\
Switching Frequency & $f_{\mathrm{s}}=27 \mathrm{kHz}$ \\
Nominal Output Voltage & $U_{\mathrm{pn}}=400 \mathrm{~V}$ \\
Nominal Output Power & $P_{\mathrm{o}}=8 \mathrm{~kW}$ \\
\hline
\end{tabular}

For $\omega t>180^{\circ}$ the injection circuit is used to create a current $i_{\text {inj }}$ which is proportional to the voltage $u_{\mathrm{yN}}$,

$$
i_{\mathrm{inj}}(\omega t)=-\hat{I}_{1} \frac{u_{\mathrm{yN}}(\omega t)}{\hat{U}_{1}} \quad \hat{I}_{1}=\frac{2 P_{\mathrm{o}}}{3 \hat{U}_{1}}
$$

where $\hat{I}_{1}$ is the peak value of the rectifier's ac input line current and $\hat{U}_{1}$ is the ac phase-to-neutral voltage amplitude. This results in sinusoidal ac input currents as shown in Fig. 3. A more detailed description of the modulation and control strategy can be found in [9], a brief description of the main 
components is given in the following.

\section{A. Input Voltage Selector}

As described above, the IAF rectifier uses an IVS, which connects each ac input phase $\mathrm{a}, \mathrm{b}, \mathrm{c}$ to either node $\mathrm{x}, \mathrm{y}$ or $\mathrm{z}$. This implies that the voltages $u_{\mathrm{xN}}, u_{\mathrm{yN}}$ and $u_{\mathrm{zN}}$ are piecewise sinusoidal, which allows to move the ac filter capacitors $C_{\overline{\mathrm{a}}, \overline{\mathrm{b}}, \overline{\mathrm{c}}}$ from nodes $\overline{\mathrm{a}}, \overline{\mathrm{b}}, \overline{\mathrm{c}}$ to nodes $\mathrm{x}, \mathrm{y}, \mathrm{z}$ as shown in Fig. 4. This shortens the commutation paths of the buck converter and the injection switches. Additionally the diode bridge currents $i_{\mathrm{x}}$ and $i_{\mathrm{z}}$ become continuous which reduces the conduction losses in the bridge diodes $D_{\overline{k x}}$ and $D_{\bar{z}}$ and in the fourquadrant switches $S_{\overline{\mathrm{ky}} \overline{\mathrm{k}}}$. The resulting rms current values can be calculated as

$$
\begin{gathered}
I_{\mathrm{D} \overline{\mathrm{k}}, \mathrm{rms}}=\hat{I}_{1} \sqrt{\frac{\sqrt{3}}{8 \pi}+\frac{1}{6}} \text { and } \\
I_{\mathrm{S} \overline{\mathrm{k}}, \mathrm{rms}}=\hat{I}_{1} \sqrt{\frac{1}{6}-\frac{\sqrt{3}}{4 \pi}} .
\end{gathered}
$$

Assuming that MOSFETs are used as synchronous rectifiers, as shown in Fig. 4, the conduction losses are reduced by $31 \%$ in the rectifier bridge and by $78 \%$ in the four-quadrant switches compared to the original circuit shown in Fig. 2 [16].

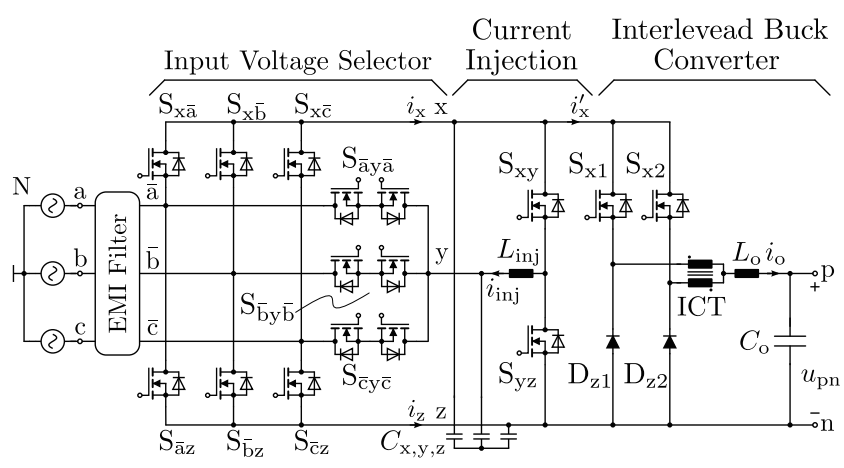

Fig. 4. Schematic of the IAF rectifier where the input filter capacitors have been moved from the ac side $(\bar{a}, \bar{b}, \bar{c})$ of the IVS to its output side $(x, y, z)$, which reduces the conduction losses [16]. The diodes $\mathrm{D}_{\overline{\mathrm{kx}}}, \mathrm{D}_{\overline{\mathrm{zk}}}$ are replaced with $\mathrm{SiC}$ MOSFETs $\mathrm{S}_{\overline{\mathrm{x}} \mathrm{k}}, \mathrm{S}_{\overline{\mathrm{kz}}}$ operating as synchronous rectifiers to further increase the efficiency. An interleaved buck converter with cells $S_{x 1}, D_{z 1}$ and $\mathrm{S}_{\mathrm{x} 2}, \mathrm{D}_{72}$ is used where $\mathrm{S}_{\mathrm{x} 1}$ and $\mathrm{S}_{\mathrm{x} 2}$ are controlled with $180^{\circ}$ phase shifted PWM signals. This lowers the current ripple in $i_{x}^{\prime}$ which leads to a lower voltage ripple at the input filter capacitors $C_{x, y, z}$. The buck converter output inductors are implemented as an inter-cell transformer (ICT) with closely coupled windings and a single output inductor $L_{\mathrm{o}}$.

\section{B. Buck Converter}

It can be seen in Fig. 4 that the buck converter's input is connected to $u_{\mathrm{xz}}$ which is a six-pulse shaped voltage provided by the IVS' rectifier bridge, cf. Fig. 3. Neglecting any voltage drops across the semiconductors and inductors, the dc output voltage $u_{\mathrm{pn}}$ can be expressed as

$$
u_{\mathrm{pn}}=\frac{3}{2} \hat{U}_{1} m \quad m \in[0,1],
$$

where $\hat{U}_{1}$ is the ac phase-to-neutral voltage amplitude and $m$ is the converter's modulation index. Note that a small distortion of the output current and the mains input currents occurs at every $60^{\circ}$ sector of the ac input voltage, i.e. at the intersection of two phase voltages $u_{\mathrm{a}, \mathrm{b}, \mathrm{c}}$. This is most likely due to the switching frequency ripple of the filter capacitor voltages $u_{\mathrm{xN}}$, $u_{\mathrm{yN}}, u_{\mathrm{zN}}$ as similar disturbances exist in the SWISS rectifier [16]. This voltage ripple is the result of the buck converter's discontinuous input current $i_{\mathrm{x}}^{\prime}$ and could be reduced with larger $C_{\mathrm{x}, \mathrm{y}, \mathrm{z}}$. However, as the capacitor voltages $u_{\mathrm{xN}}, u_{\mathrm{yN}}, u_{\mathrm{zN}}$ are piecewise sinusoidal they generate reactive power which is typically limited to $5 \%$ to $10 \%$ of the converter's active power rating.

\section{Interleaved Buck Converter}

In order to reduce the buck converter's input current ripple and hence the mains input current distortions and the electromagnetic noise emission of the rectifier, an interleaved buck converter can be used, as shown in Fig. 4. By modulating the switches $\mathrm{S}_{\mathrm{x} 1}$ and $\mathrm{S}_{\mathrm{x} 2}$ with $180^{\circ}$ phase shifted PWM signals the peak-to-peak ripple in $i_{x}^{\prime}$ is reduced by approximately a factor of two and the ripple frequency is doubled due to cancellation of harmonics.

The dc output filter of the interleaved buck converter can be implemented by a combination of an inter-cell transformer (ICT) with closely coupled windings and a single inductor instead of two separate inductors. Using ICTs for interleaved dc-dc converters has been extensively described in literature and has been shown to result in a reduction of the magnetic component's volume, losses and weight [17]-[19].

In Fig. 5 the basic operating principle is shown for a duty cycle of $d_{\mathrm{x}}=0.75$ and $180^{\circ}$ phase shifted PWM signals. The two cells $\mathrm{S}_{\mathrm{x} 1} / \mathrm{D}_{\mathrm{z} 1}$ and $\mathrm{S}_{\mathrm{x} 2} / \mathrm{D}_{\mathrm{z} 2}$ produce the output voltages $\mathrm{u} 1$ and $\mathrm{u} 2$ shown in Fig. 5(e). These can be transformed into the corresponding common-mode $(\mathrm{cm})$ and differential-mode (dm) voltages $u_{\mathrm{cm}}$ and $u_{\mathrm{dm}}$, cf. Figs. 5(f)-(g)

$$
\begin{aligned}
& u_{\mathrm{cm}}=\frac{u_{1}+u_{2}}{2}, \\
& u_{\mathrm{dm}}=\frac{u_{1}-u_{2}}{2} .
\end{aligned}
$$

By replacing the ICT with the equivalent circuit shown in Fig. 5(b) the circuit diagram Fig. 5(c) results, which can be decomposed into two uncoupled circuits as shown in Fig. $5(\mathrm{~d})$. It can be seen that the $\mathrm{cm}$ voltage $u_{\mathrm{cm}}$, which is applied to the dc output inductor $L_{\mathrm{o}}$ and the ICT's leakage inductance $L_{\sigma}$, switches twice per switching frequency period and has a voltage step height of half the input voltage $u_{\mathrm{xz}}$.

Note that unbalances in the system, such as unequal onstate resistances of the switches, duty cycle differences and mismatched PCB track resistances can lead to unbalanced ICT currents $i_{\mathrm{o} 1} \neq i_{\mathrm{o} 2}$. This results in a dc magnetization cur- 


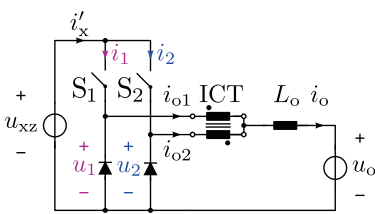

(a)

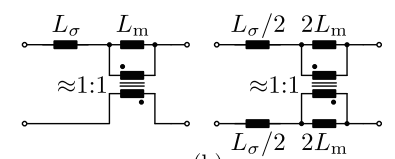

(b)

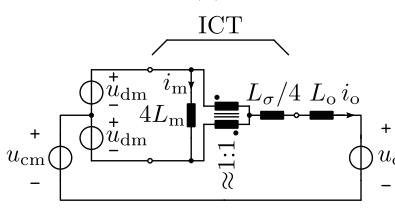

(c)

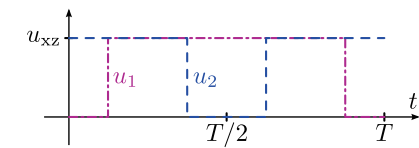

(e)
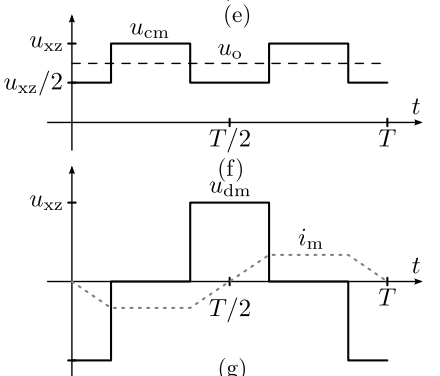

(g)

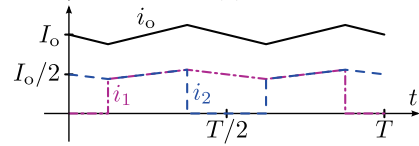

$T / 2$

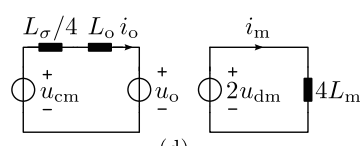

(d)

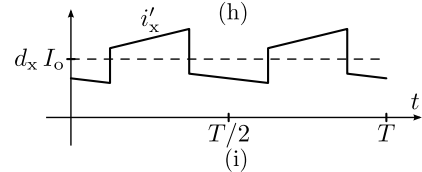

Fig. 5. Operating principle of an interleaved buck converter using a close-coupled inter-cell transformer (ICT). (a) shows the basic circuit diagram, the switches are controlled with $180^{\circ}$ phase shifted PWM signals as shown in (e). Replacing the ICT with the equivalent circuit of an non-ideal transformer as shown in (b) and separating voltages $u_{1}$ and $u_{2}$ into common-mode $(\mathrm{cm})$ and differential-mode $(\mathrm{dm})$ voltages, $u_{\mathrm{cm}}$ and $u_{\mathrm{dm}}$, yields the circuit shown in (c). It can be seen that $u_{\mathrm{cm}}$ is applied to $L_{\sigma}$ and $L_{o}$ and can be used to control the output current $i_{o}$, while udm controls the ICT's magnetizing current $i_{\mathrm{m}}$ as shown in (d).

rent of the ICT,

$$
i_{m}=\frac{i_{\mathrm{o} 1}-i_{\mathrm{o} 2}}{2}
$$

that could lead to a saturation of the core material. However, the dm voltage $u_{\mathrm{dm}}$ is applied to the ICT's magnetizing inductance $L_{\mathrm{m}}$ and can be used by an active control circuit to ensured an equal current sharing $i_{\mathrm{o} 1} \approx i_{\mathrm{o} 2}$ in the ICT windings. Strategies for active current balancing control in ICTs have been described in the literature [20]-[21].

\section{Life Cycle Cost Based Converter Design}

The design of any power electronic converter is essentially aiming for a best possible overall compromise of multiple trade-offs which result from couplings between different components concerning stresses and utilization. For example increasing the switching frequency reduces the peak-to-peak flux ripple of magnetic components which typically leads to smaller and/or more efficient components, but also increases the switching losses of the semiconductors. This in turn requires a larger heat sink and which could overcompensate the volume reduction achieved in the magnetic components. Similar trade-offs also exist on the component level, e.g. increasing the number of turns in an inductor decreases the core losses at the expense of increased winding losses. Fur- thermore even for a given fixed switching frequency multiple combinations of volumes or sizes of the different components can lead to similar power densities and efficiencies. Designing an optimal converter becomes even more challenging if more than a single circuit topology and/or several different core and winding materials are taken into account. Due to these tradeoffs a single optimal converter can typically not be found but rather a range of pareto optimal designs can be calculated which achieve e.g. the highest efficiency for a given power density and vice versa.

These trade-offs can be simplified by introducing a singlevalued objective function such as life cycle cost (LCC). As described in [22] the capital equivalent worth of one watt of continuous dissipation can be used to select components in order to minimize the LCC of that component. Combined with cost models, the switching frequency, semiconductors and magnetic components are selected to achieve minimal life cycle cost for a given service life time assuming continuous operation at rated power as will be shown in the following for the IAF rectifier [23].

Given some basic economic parameters, such as interest and inflation rates, the capital-equivalent worth of a continuously dissipated watt of ac power can be estimated. In 2008 the authors of [22] estimated an average value of $\$ 14$ per watt for the US market and 15 years of service life, which implies that up to $\$ 14$ could be invested now in order to reduce the equipment's power consumption by one watt over the next 15 years. Although the prices for electric power show a considerable geographical variation (approximately a factor of 5 in the US), the authors conclude that the cost of dissipation significantly overshadows the first cost for telecom power supplies.

\section{A. Semiconductor Technology Comparison}

An example calculation for the input voltage selector fullwave rectifier $D_{\overline{\mathrm{kx}}}, \mathrm{D}_{\overline{\mathrm{z}} \mathrm{k}} / \mathrm{S}_{\mathrm{x} \overline{\mathrm{k}}}, \mathrm{S}_{\overline{\mathrm{kz}}}$ is shown in Fig. 6, where

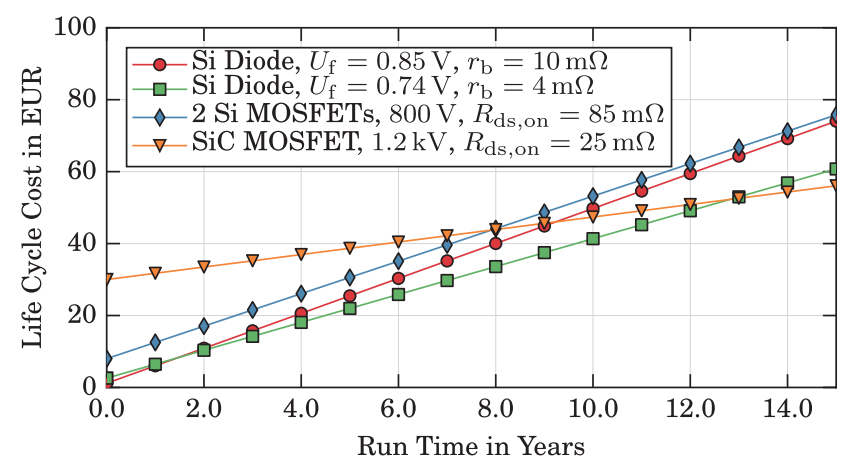

Fig. 6. Comparison of life cycle cost for different implementations of the diode bridge rectifier $\mathrm{D}_{\overline{\mathrm{kx}}}, \mathrm{D}_{\overline{\mathrm{zk}}}$ of the IVS with $I_{\mathrm{rms}}=8.1 \mathrm{~A}, I_{\mathrm{avg}}=4.6 \mathrm{~A}\left(P_{\mathrm{o}}=\right.$ $8 \mathrm{~kW}$ ) and a capital equivalent worth of EUR 0.12 per $\mathrm{kWh}$ [22]. Switching losses are neglected as the IVS commutates at twice the mains frequency only. It can be seen that the significantly higher first cost of a SiC MOSFET is compensated by the reduced conduction losses of the device achieving roughly the same life cycle cost as Si diodes and Si MOSFETs for run times of approximately ten years, assuming continuous operation at rated power. 
a capital equivalent worth of $\gamma=$ EUR 0.12 per kWh (approximately USD 0.13 at time of publication) is assumed. Neglecting switching losses in the IVS, the device losses can be directly determined from the rms and average currents found by numerical simulation, resulting in $I_{\mathrm{rms}}=8.1 \mathrm{~A}$ and $I_{\text {avg }}$ $=4.6 \mathrm{~A}$ for an $8 \mathrm{~kW}$ system. Assuming a service life time of 10 years or more, a SiC MOSFET with a high initial cost of approximately EUR 30 and low on state resistance achieves the same or lower life cycle cost than conventional Si diodes with an initial cost of EUR 2.6. The same holds for a parallel connection of two Si MOSFETs with a first cost of approximately EUR 8. Note that all devices are operated far below their thermal limits, e.g. $1.7 \mathrm{~W}$ of conduction losses result for the $\mathrm{SiC}$ MOSFTEs, $\approx 4 \mathrm{~W}$ for the Si diodes and Si MOSFETs while all devices are rated for more than $100 \mathrm{~W}$ of continuous power dissipation.

\section{B. Semiconductors without Switching Losses}

The calculation shown in Fig. 6 is based on a selection of standard semiconductor devices which might not achieve the lowest possible LCC. Using more than one device in parallel reduces the total on-state resistance $R_{\mathrm{ds}, \text { on }}$ of MOSFETs or the (differential) bulk resistances $r_{\mathrm{b}}$ of diodes which lowers the conduction losses. This reduces the cost of dissipation during system operation, but increases the first cost as more devices are used, which implies that the resulting LCC is a function of the number $n$ of devices used in parallel. For a MOSFET, continuously conducting the current $I_{\text {rms }}$ for the run time $t_{\mathrm{r}}$, without switching losses the corresponding LCC $\Lambda$ can be expressed as

$$
\Lambda_{\mathrm{M}}(n)=\underbrace{\gamma t_{\mathrm{r}} \frac{R_{\mathrm{ds}, \mathrm{on}}}{n} I_{\mathrm{rms}}^{2}}_{\text {Cost of Dissipation, } \Gamma_{\mathrm{M}}}+\underbrace{\sigma_{\mathrm{M}} n}_{\text {First Cost, } \Sigma_{\mathrm{M}}},
$$

where $\sigma_{\mathrm{M}}$ is the cost of a single MOSFET with an onstate resistance $R_{\mathrm{ds}, o n}$. A plot of the resulting values for $t_{\mathrm{r}}=10$ years,

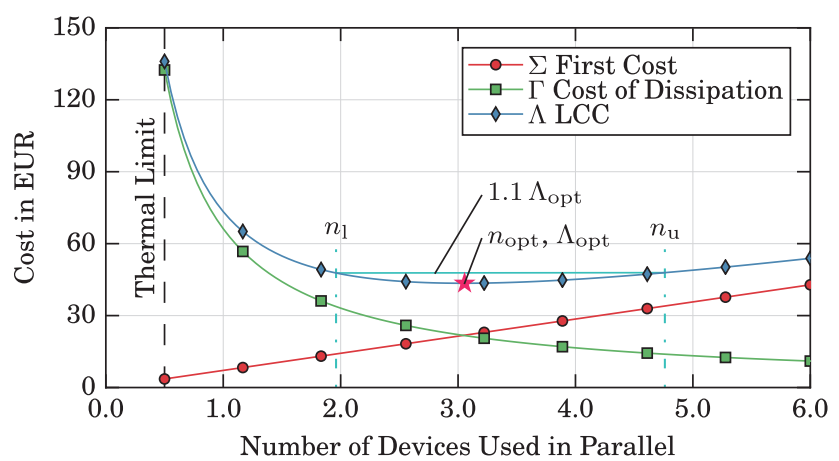

Fig. 7. First cost, cost of dissipated energy and life cycle cost (LCC) as a function of the number of devices connected in parallel for the rectifier bridge $\mathrm{S}_{\overline{\mathrm{x}}}, \mathrm{S}_{\overline{\mathrm{k} z}}$ at nominal operation with $I_{\mathrm{rms}}=8.1 \mathrm{~A}\left(P_{\mathrm{o}}=8 \mathrm{~kW}\right)$. A SiC MOSFET with $R_{\mathrm{ds}, \mathrm{on}}=96 \mathrm{~m} \Omega$ and a cost of EUR 7.14 is considered as unit device together with a capital equivalent worth of $\gamma=$ EUR 0.12 per kWh and a run time of $t_{\mathrm{r}}=10$ years.
$R_{\mathrm{ds}, \mathrm{on}}=96 \mathrm{~m} \Omega$ and $\sigma_{\mathrm{M}}=$ EUR 7.14 is shown in Fig. 7. For a given $t_{\mathrm{r}}$ the optimal number of devices $n_{\text {opt }}$, which achieves minimal life cycle cost, can be derived by minimizing (8) with respect to $n$ as

$$
\begin{aligned}
n_{\mathrm{opt}} & =\sqrt{\gamma t_{\mathrm{r}} \frac{R_{\mathrm{ds}, \mathrm{on}}}{\sigma_{\mathrm{M}}}} I_{\mathrm{rms}}, \\
\Gamma_{\mathrm{M}, \mathrm{opt}} & =\Sigma_{\mathrm{M}, \mathrm{opt}}=\sqrt{\gamma t_{\mathrm{r}} R_{\mathrm{ds}, \mathrm{on}} \sigma_{\mathrm{M}}} I_{\mathrm{rms}}, \\
\Lambda_{\mathrm{M}, \mathrm{opt}} & =\Gamma_{\mathrm{M}, \mathrm{opt}}+\Sigma_{\mathrm{M}, \mathrm{opt}}=2 \sqrt{\gamma t_{\mathrm{r}} R_{\mathrm{ds}, \mathrm{on}} \sigma_{\mathrm{M}}} I_{\mathrm{rms}}
\end{aligned}
$$

Note that a certain minimum $n_{\min }$ exists due to the thermal limits of the device and the cooling system as indicated in Fig. 7. However, even for short run times of $t_{\mathrm{r}} \approx 1$ year the optimal $n$ is typically larger than $n_{\min }$.

This optimization can be extended from MOSEFTs to diodes modeled by a constant forward voltage drop $U_{\mathrm{f}}$ connected in series with a (differential) bulk resistance $r_{\mathrm{b}}$ as

$$
\Lambda_{\mathrm{D}}(n)=\gamma t_{\mathrm{r}} \frac{r_{\mathrm{b}}}{n} I_{\mathrm{rms}}^{2}+\gamma t_{\mathrm{r}} U_{\mathrm{f}} I_{\mathrm{avg}}+\sigma_{\mathrm{M}} n .
$$

In this case $n_{\text {opt }}$ does not depend on Uf, however the losses and hence the cost of dissipation $\Gamma$ increases. An example calculation for different run times is shown in Fig. 8 where a $96 \mathrm{~m} \Omega \mathrm{SiC}$ MOSFET and Si diode with $U_{\mathrm{f}}=0.74 \mathrm{~A}$ and $r_{\mathrm{b}}=$ $4 \mathrm{~m} \Omega$ are considered as unit elements. For both, MOSFETs and diodes the optimal $n$ increases proportional to $\sqrt{t_{\mathrm{r}}}$, however for Si diodes the resulting losses show little variation due to $U_{\mathrm{f}}$. As the first cost of the considered diode is $\approx 6$
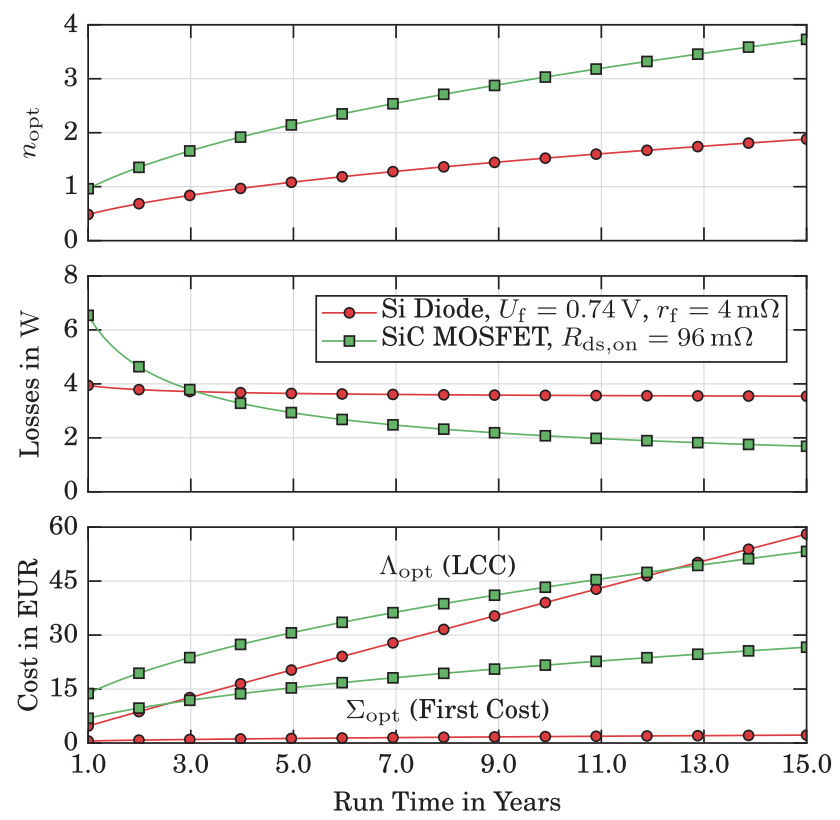

Fig. 8. Optimization results for Si Diodes and $\mathrm{SiC}$ MOSFETs showing the optimal (lowest LCC) number of parallel devices, resulting device losses, first and life cycle cost as a function of the run time $t_{\mathrm{r}}$ in years. The same parameters as in Fig. 7 are used. 
times lower than the MOSFET's the Si diodes achieves lower LCC for small $t_{\mathrm{r}}$ while the SiC MOSFET achieves lower $\mathrm{LCC}$ for $t_{\mathrm{r}} \geq 12.5$ years.

\section{Device Selection}

So far $n$ has been assumed as a real number which has to be rounded to the next integer or to the next $R_{\mathrm{ds}, \text { on }}$ value available from the device manufacturer. This leads to a suboptimal LCC, but it can seen in Fig. 7 that $\Lambda(n)$ is flat around the optimum. If a certain allowed increase $\alpha$ in LCC is assumed, a resulting lower and upper bound $\left(n_{1}, n_{\mathrm{u}}\right)$ for permissible values of $n$ can be calculated using (8) as

$$
\begin{aligned}
& n_{\mathrm{l}}(\alpha)=n_{\mathrm{opt}}\left(1+\alpha-\sqrt{(1+\alpha)^{2}-1}\right) . \\
& n_{\mathrm{u}}(\alpha)=n_{\mathrm{opt}}\left(1+\alpha+\sqrt{(1+\alpha)^{2}-1}\right) .
\end{aligned}
$$

To derive the required granularity of $n$ the ratio $r_{\mathrm{n}}$ of $n_{\mathrm{u}}$ and $n_{1}$ can be calculated,

$$
r_{\mathrm{n}}(\alpha)=\frac{n_{\mathrm{u}}(\alpha)}{n_{\mathrm{l}}(\alpha)} \quad r_{\mathrm{n}}(0.1)=2.43,
$$

which does not depend on any device specific parameters in (8) and results in a value of 2.43 for $\alpha=0.1$ (also shown in Fig. 7). This implies that the achievable LCC is at most $10 \%$ higher than the theoretical optimum if the ratio between two consecutive $R_{\mathrm{ds}, \text { on }}$ values of the available devices is 2.4 or less.

\section{Including Switching Losses}

In the derivation (9), which gives the LCC optimal number of device, it was assumed that switching losses can be neglected which is typically not the case for the half bridge $\mathrm{S}_{\mathrm{xy}}, \mathrm{S}_{\mathrm{yz}}$ used in the current injection circuit. The calculation can be extended by fitting a second order polynomial to measured hard switching losses (turn-on and turn-off) for the switched voltage,

$$
E_{\mathrm{sw}}\left(I_{\mathrm{sw}}\right) \approx E_{0}+E_{1} I_{\mathrm{sw}}+E_{2} I_{\mathrm{sw}}^{2}
$$

where $I_{\mathrm{sw}}$ is the switched current. Switching losses measured in [23] for a half bridge of two C2M0080120 SiC MOSFETs and $600 \mathrm{~V}$ dc link voltage at various $I_{\mathrm{sw}}$ are shown in Fig. 9 together with a second order polynomial fitted by least squares regression. If $n$ devices are used in parallel, equal current sharing is assumed and the switching frequency current ripple in the output current can be neglected the total switching losses can then be calculated as

$$
E_{\mathrm{sw}} \approx n\left[E_{0}+E_{1} \frac{I_{\mathrm{sw}, \mathrm{avg}}}{n}+E_{2}\left(\frac{I_{\mathrm{sw}, \mathrm{rms}}}{n}\right)^{2}\right] \text {, }
$$

where $I_{\mathrm{sw}}$, avg and $I_{\mathrm{sw}, \text { rms }}$ are the average and rms values of the switched current over one mains voltage period. It can be seen that the terms in (17) have the same dependency on $n$ as those in (8) which implies that the optimal number of devices which achieves minimal LCC for a given $f_{\mathrm{sw}}$ can be calculated as

$$
n_{\mathrm{opt}}=\sqrt{\gamma t_{\mathrm{r}} \frac{R_{\mathrm{ds}, \mathrm{on}} I_{\mathrm{rms}}^{2}+f_{\mathrm{sw}} E_{2} I_{\mathrm{sw}, \mathrm{rms}}^{2}}{\sigma_{\mathrm{M}}+\gamma t_{\mathrm{r}} f_{\mathrm{sw}} E_{0}}} .
$$

The resulting $n_{\mathrm{opt}}$, first cost $\sum_{\mathrm{opt}}$ and LCC $\Lambda_{\mathrm{opt}}$ for the injection switches $S_{x y}, S_{y z}$ are shown as function of the switching frequency $f_{\text {sw }}$ in Fig. 10. It can be seen that $\mathrm{n}_{\mathrm{opt}}$ and therefore $\sum_{\mathrm{opt}}$ decrease with $f_{\mathrm{sw}}$ while the cost of dissipation $\Gamma$ increases, mainly due to the switching losses.

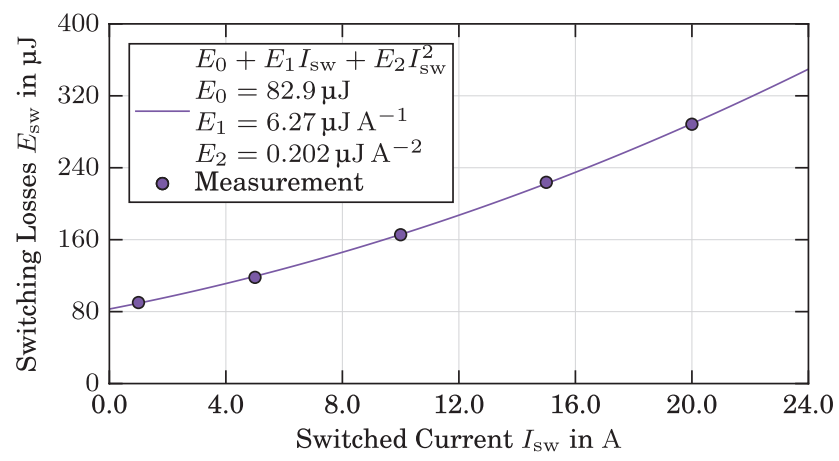

Fig. 9. Sum of turn-on and turn-off losses $E_{\mathrm{sw}}$ measured in [23] as a function of the switched current $I_{\text {sw }}$ for a half bridge of $C 2 M 0080120 \mathrm{SiC}$ MOSFETs with $600 \mathrm{~V} \mathrm{dc} \mathrm{link} \mathrm{voltage} \mathrm{at} 25^{\circ} \mathrm{C}$. Additionally a second order polynomial function fitted by least squares regression is shown and the fitted parameters are given in the legend.
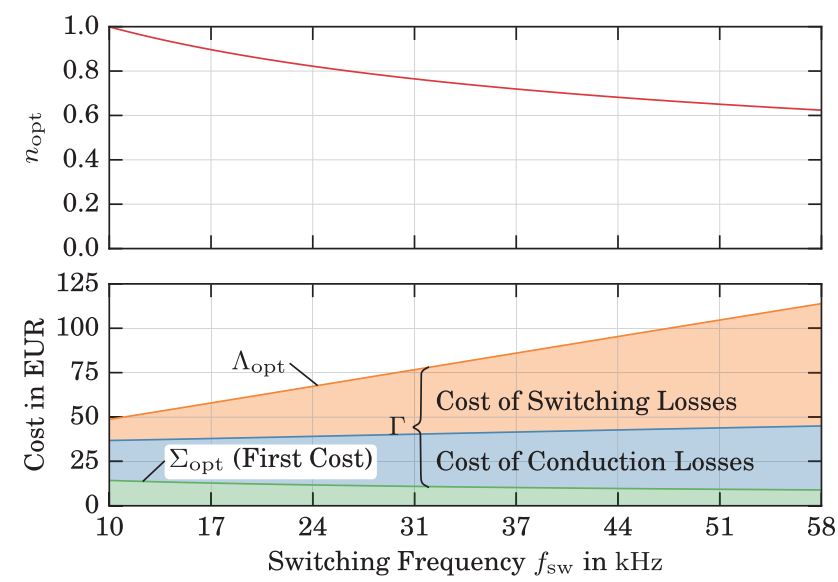

Fig. 10. Life cycle cost and optimal number of MOSFETs in parallel nopt for a half bridge built with $C 2 M 0080120$ devices for the injection Switches Sxy and Syz with an rms current $I_{\mathrm{rms}}=I_{\mathrm{sw} \text {, rms }}=4.7 \mathrm{~A}$ and an average switched current of $I_{\mathrm{sw}, \text { avg }}=4.1 \mathrm{~A}$ as a function of the switching frequency for $t_{\mathrm{r}}=10$ years.

\section{E. Magnetic Components}

The dimensioning of magnetic components is performed 
with a similar algorithm, but unlike for semiconductor devices analytical solutions can typically not be found. For a given $f_{\text {sw }}$ the current and voltage stresses created by the converter can be determined and for a selected core material, shape and size the optimal number of turns, which minimizes the sum of core and winding losses, can be determined by numerical optimization methods. Using the losses and cost models for core and winding materials the inductor's LCC is calculated, which allows the selection of an optimal core size achieving minimal LCC for the given $f_{\text {sw }}$ and $t_{\mathrm{r}}$.

\section{F. Optimal Switching Frequency Selection}

Once the optimal LCC of semiconductors and magnetic components has been calculated as a function of $f_{\mathrm{sw}}$ these can be added in order to select a switching frequency which achieves the lowest total LCC. An example calculation for the injection circuit with the switches $S_{\mathrm{xy}}, S_{\mathrm{yz}}$ and the inductor $L_{\text {inj }}$ is shown in Fig. 11, where it can be seen that the inductor's first cost $\sum_{\text {Linj }}$ and cost of dissipation $\Gamma_{\text {Linj }}$ and hence its LCC decrease with increasing $f_{\text {sw }}$ as opposed to the increasing LCC of the semiconductors, resulting in an optimal $f_{\text {sw }}$. A total run time of $t_{\mathrm{r}}=10$ years is assumed in this example.

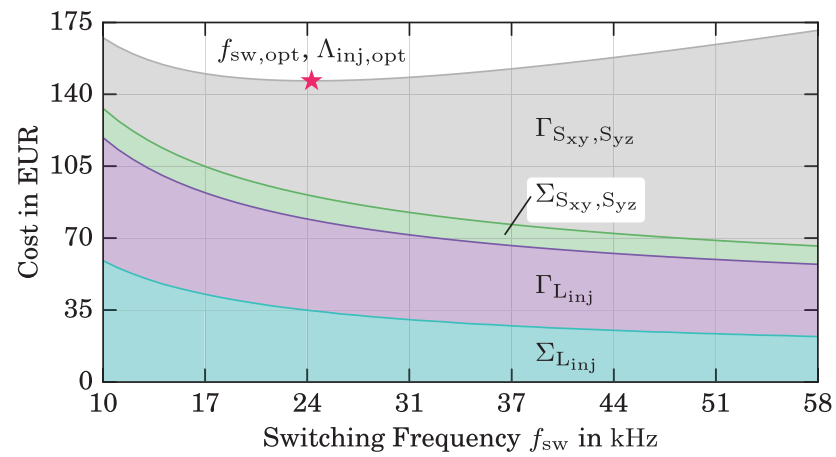

Fig. 11. Example showing the selection of a switching frequency $f_{\mathrm{sw}}$ which achieves the lowest sum of LCCs for the injection switches $\mathrm{S}_{\mathrm{xy}}, \mathrm{S}_{\mathrm{yz}}$ and the corresponding inductor $L_{\text {inj }}$ for $t_{\mathrm{r}}=10$ years, not considering any other components of the rectifier.

\section{G. Global Optimization Algorithm}

In a final step the algorithm outlined above can be extended to include the entire rectifier to determine the optimal $f_{\text {sw }}$ and all optimal component sizes by minimizing the systems LCC

$$
\Lambda_{\text {sys }, \text { opt }}\left(t_{\mathrm{r}}\right)=\min _{f_{\mathrm{sw}}} \sum_{k} \Lambda_{\mathrm{k}, \mathrm{opt}}\left(f_{\mathrm{sw}}, t_{\mathrm{r}}\right) .
$$

The design procedure sweeps over all relevant switching frequencies $f_{\mathrm{sw}}$ and considered run times $t_{\mathrm{r}}$, where for each tupel $\left(f_{\mathrm{sw}}, t_{\mathrm{r}}\right)$ and all components $k$ (e.g. switches, inductors, etc.) of the system an optimal relative size $n_{\mathrm{k}, \text { opt }}$ can be determined which achieves minimal LCC $\Lambda_{\mathrm{k}, \text { opt }}$ for component $k$. This implies that all components can be designed independently of each other which simplifies the optimization procedure. Once all components have been selected, their life cycle costs can be summed up which yields the system's LCC for the considered $\left(f_{\mathrm{sw}}, t_{\mathrm{r}}\right)$ : Once all designs have been calculated the switching frequency achieving lowest overall $\mathrm{LCC}$ is selected for each $t_{\mathrm{r}}$ considered in the analysis.

\section{H. Auxiliary Components}

The losses, volumes and costs of other components, such as gate drive circuits, DSP/FPGA, capacitors, PCBs, heat sinks, fans, EMI filter, etc have to be considered as well. While their contribution to the overall converter volume, and LCC can be significant, they are almost independent of the design point in the considered application. Therefore these auxiliary components have been considered in the design but were not part of the optimization.

\section{Optimization Results}

Fig. 12 shows the achievable minimal LCC $\Lambda_{\text {sys,opt }}\left(t_{\mathrm{r}}\right)$ and the resulting first cost $\sum_{\text {sys,opt }}\left(t_{\mathrm{r}}\right)$ as a function of run time calculated by the optimization outlined above. It can be seen that the first cost of the optimal systems is less than $30 \%$ of the total life cycle cost for a run time of 10 years or more. Furthermore, the LCC is comparable for all three core materials considered in the optimization. Designs using amorphous cores are expected to have slightly higher LCC than systems with nanocrystalline or ferrite cores, which is due to the higher core losses of amorphous materials.

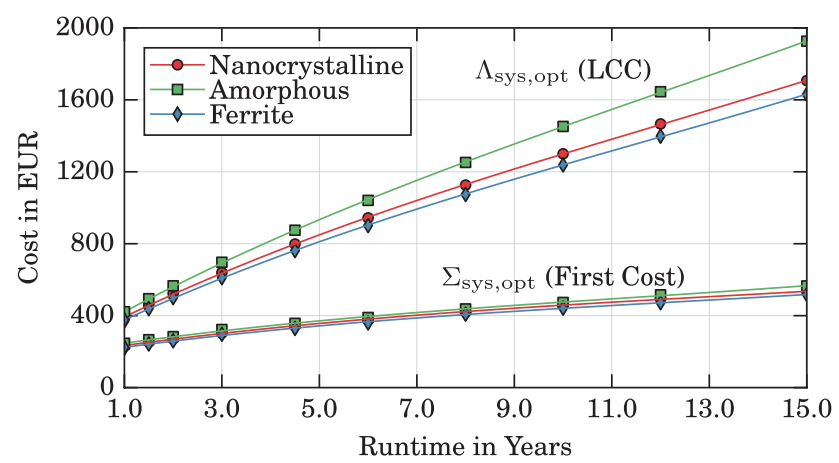

Fig. 12. Minimal achievable LCC and according first cost of optimal converter designs as a function of run time for different inductor core materials. It can be seen that for a run time of ten years, the first cost is $<30 \%$ of the total life cycle cost. The optimization results in similar first costs for all three core materials, however the life cycle cost of designs with ferrite and nanocrystalline inductors is slightly lower compared to solutions with amorphous cores.

However, the volumes and switching frequencies of the designed converters differ significantly as shown in Fig. 13; the resulting efficiency as function of $t_{\mathrm{r}}$ is shown in Fig. 14. For short run times ( $\leq 2$ years) converters with high switching frequencies and high power densities achieve minimal LCC as opposed to long run times ( $\geq 10$ years) where designs with approximately half the switching frequency, twice the volume and half the losses result. Furthermore, these results show that very high efficiencies of up to $99 \%$ are economically feasible with available state-of-the-art $\mathrm{SiC}$ 


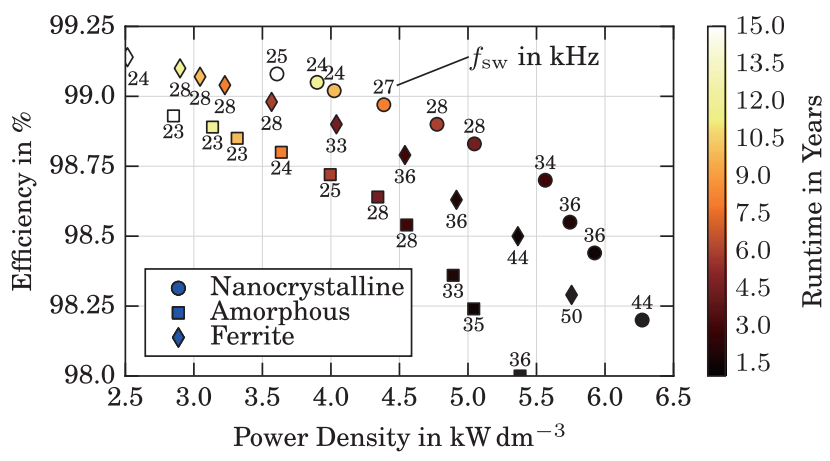

Fig. 13. Optimization results showing power density, efficiency and switching frequency $f_{\mathrm{sw}}$ of designs achieving minimal LCC for different run times and inductor core materials of ICT, $L_{\text {inj }}$ and $L_{\mathrm{o}}$.

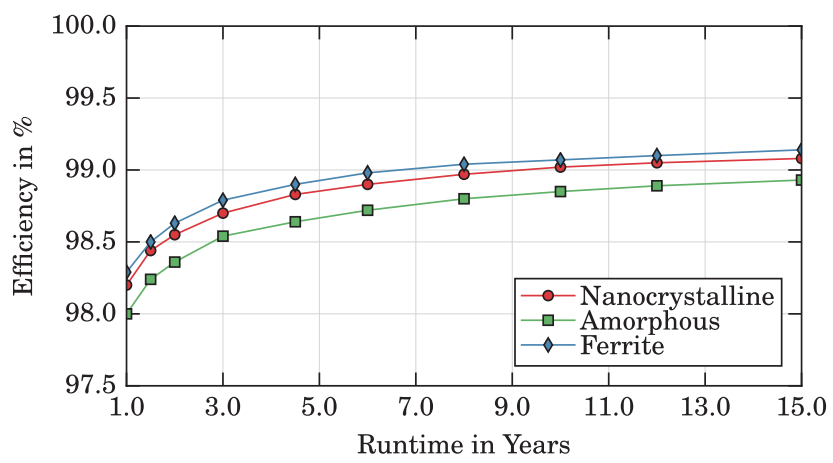

Fig. 14. Calculated efficiencies of life cycle cost optimal converter designs for different run times and core materials.

switches and core materials. Note that three-phase rectifiers based on Si and SiC MOSFETS with slightly lower efficien- cies have been reported in the literature [24], [25], however without considering cost.

\section{J. Selected Design}

Based on the numerical optimization results the design point with $t_{\mathrm{r}}=10$ years, $f_{\mathrm{sw}}=27 \mathrm{kHz}$, a power density of 4.0 $\mathrm{kWdm}^{-3}$ and an efficiency of $99 \%$ was selected to implement a hardware prototype. FINEMET nanocrystalline cores with helical windings (cf. Fig. 15) are used as they achieve considerably higher power density compared to designs based on ferrite. Detailed results of the optimization are shown in Fig. 16: for systems with a run time of 10 years or more, it can be seen that the semiconductors and heat sinks contribute about half of the first cost, life cycle cost and losses, but only about $10 \%$ to $20 \%$ of the total volume. Furthermore, the auxiliary components, such as PCBs, gate drivers, FPGA/DSP etc. have a significant contribution to both first cost and life cycle cost which implies that they cannot be neglected in the design process.

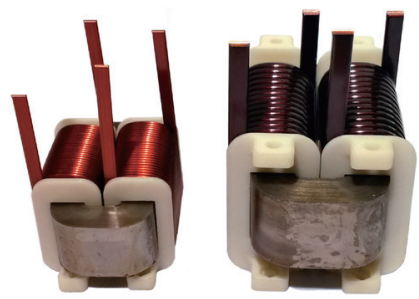

Fig. 15. Picture of $L_{\text {inj }}$ and $L_{0}$, implemented using nanocrystalline C cores and helical windings. A boxed volume of $88 \mathrm{~cm}^{3}$ and $249 \mathrm{~cm}^{3}$ results for the two inductors. The specifications and parameters of the implemented inductors are given in Table II.

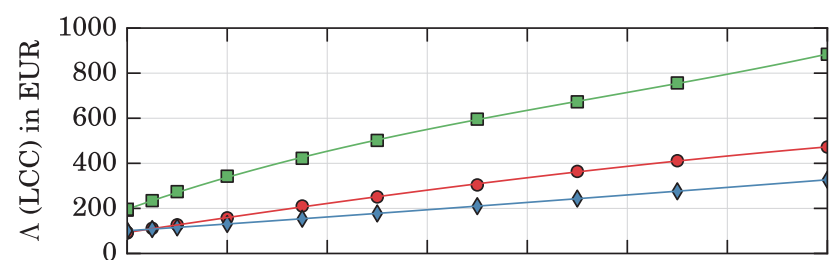

(a)

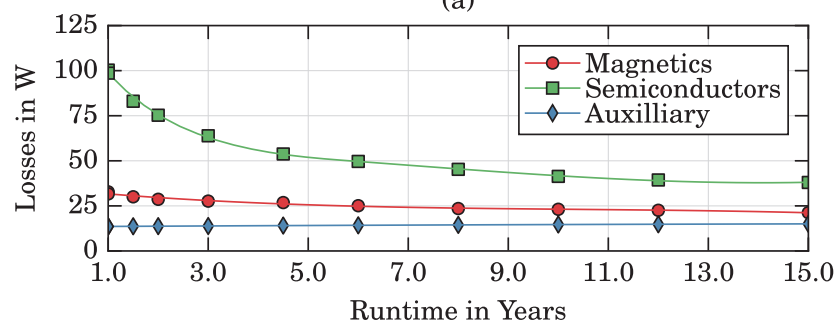

(c)

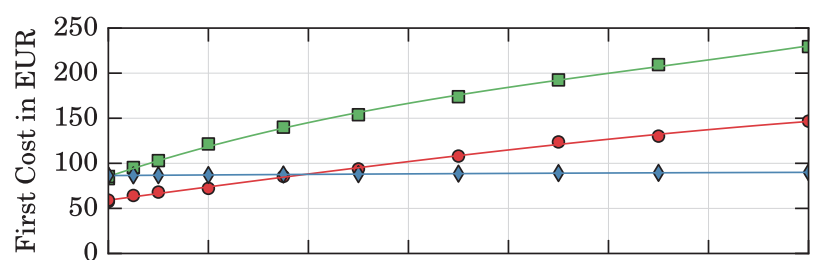

(b)

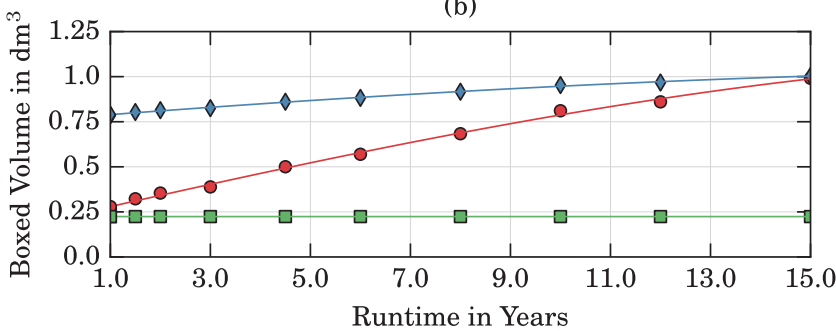

(d)

Fig. 16. Spline interpolated results of the numerical optimization (markers) for the semiconductors (incl. heatsinks), magnetics and remaining components (e.g. fans, gate drivers, PCBs, DSP/FPGA, capacitors, EMI filter) of the circuit shown in Fig. 4. Nanocrystalline cores with helical windings are used for all magnetic components as they offer the best performance in this case, cf. Fig. 13. Plot (a) shows the optimal LCC $\Lambda\left(t_{\mathrm{r}}\right)$, (b) shows the corresponding optimal first $\operatorname{cost} \sum\left(t_{\mathrm{r}}\right)$, (c) the losses occurring in the components and (d) their boxed volume. It can be seen that the semiconductors contribute about half of the first cost and losses and hence the life cycle cost, but only $\approx 10 \%$ to $20 \%$ of the total converter volume. 


\section{Hardware Prototype}

Using the optimization results presented in the previous chapter, an $8 \mathrm{~kW}$, prototype IAF rectifier with a switching frequency of $f_{\mathrm{sw}}=27 \mathrm{kHz}$, according to the specifications given in Table I, was implemented. A picture of the hardware is shown in Fig. 17 and its main components are listed in Table II.

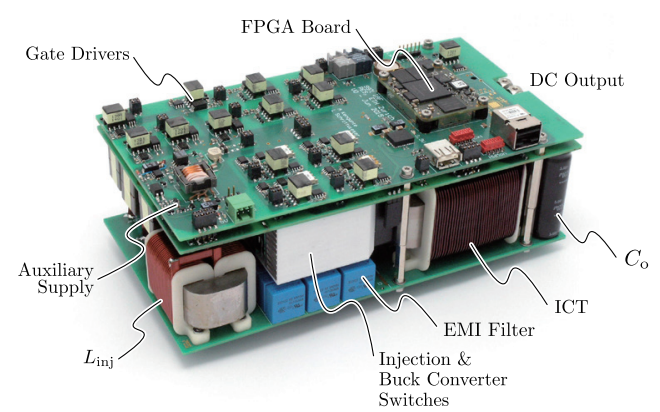

Fig. 17. Picture of the hardware prototype, measuring $220 \mathrm{~mm} \times 118 \mathrm{~mm} \times$ $77 \mathrm{~mm}(8.66$ in $\times 4.65$ in $\times 3.03$ in). This results in a power density of 4.0 $\mathrm{kWdm}^{-3}\left(65 \mathrm{~W} \mathrm{in}^{-3}\right)$.

TABLE II

Components Used in the Hardware Prototype

\begin{tabular}{llll}
\hline \hline & $L_{\text {inj }}$ & ICT & $L_{\mathrm{o}}$ \\
Core & F3CC-6.3 & F3CC-25 & F3CC25 \\
Wire & $1 \times 4 \mathrm{~mm}$ & $1 \times 6 \mathrm{~mm}$ & $2.4 \times 6 \mathrm{~mm}$ \\
Turns & 52 & $36: 36$ & 30 \\
Inductance & $750 \mu \mathrm{H}$ & $3 \mathrm{mH}$ & $300 \mu \mathrm{H}$ \\
Volume & $88 \mathrm{~cm}^{3}$ & $245 \mathrm{~cm}^{3}$ & $249 \mathrm{~cm}^{3}$ \\
Losses & $4.8 \mathrm{~W}$ & $6.7 \mathrm{~W}$ & $5.5 \mathrm{~W}$ \\
\hline $\mathrm{S}_{\mathrm{x} \mathrm{k}}, \mathrm{S}_{\overline{\mathrm{kx}}}$ & $\mathrm{C} 2 \mathrm{M} 0025120$ & & $P_{\text {loss }}=1.7 \mathrm{~W}$ \\
$\mathrm{~S}_{\mathrm{ky} \overline{\mathrm{k}}}$ & $\mathrm{C} 2 \mathrm{M} 0080120$ & & $P_{\text {loss }}=0.8 \mathrm{~W}$ \\
$\mathrm{~S}_{\mathrm{xy}}, \mathrm{S}_{\mathrm{yz}}$ & $\mathrm{C} 2 \mathrm{M} 0080120$ & & $P_{\text {loss }}=2.3 \mathrm{~W}$ \\
$\mathrm{~S}_{\mathrm{x} \mathrm{x}}, \mathrm{S}_{\mathrm{x} 2}$ & $\mathrm{C} 2 \mathrm{M} 0025120$ & & $P_{\text {loss }}=6.3 \mathrm{~W}$ \\
$\mathrm{D}_{\mathrm{z} 1}, \mathrm{D}_{\mathrm{z} 2}$ & $\mathrm{C} 4 \mathrm{D} 40120 \mathrm{D}$ & & $P_{\text {loss }}=2.7 \mathrm{~W}$ \\
\hline \hline
\end{tabular}

A more detailed distribution of the calculated component losses for the implemented prototype at nominal operating conditions and the corresponding component volumes are shown in Fig. 18. About $50 \%$ of the total losses occur in the semiconductors. Core and winding losses in the main magnetic components $L_{\mathrm{o}}, I C T$ and $L_{\mathrm{inj}}$ account for $\approx 22 \%$ of the total losses. The remaining $28 \%$ occur in the EMI filter, the PCB tracks, and other elements such as fans, gate drivers,

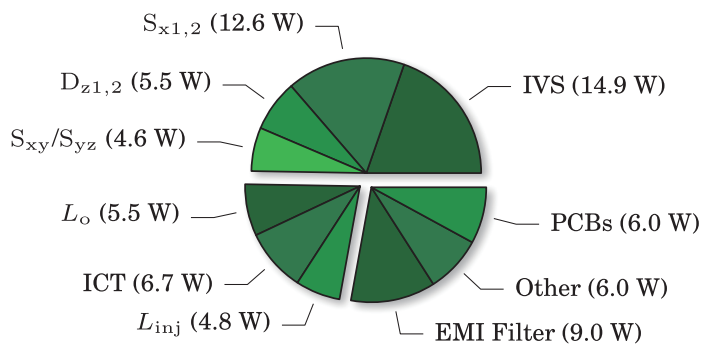

(a)

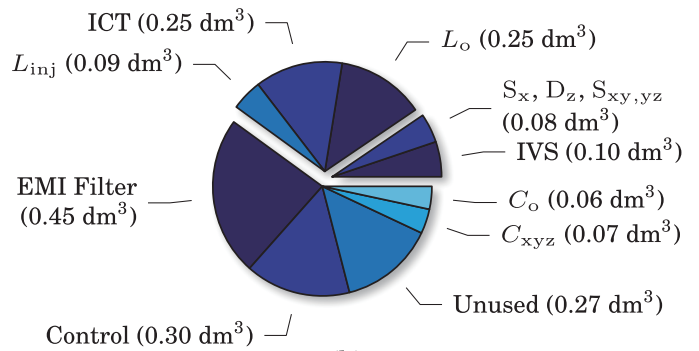

(b)

Fig. 18. The calculated distribution of losses for the selected design point at nominal operation is shown in (a), the corresponding component volumes are shown in (b). Category other includes fans, gate drivers, FPGA, ADCs, current sensors, auxiliary supply, etc.

FPGA, current sensors etc. Measurement results of the prototype converter are presented in the following.

\section{A. AC Input Currents}

In Fig. 19 measurement results of the prototype rectifier operated at full load and nominal input voltage are shown. Sinusoidal input currents with slight distortions at the mains voltage sector boundaries result as expected from simula-
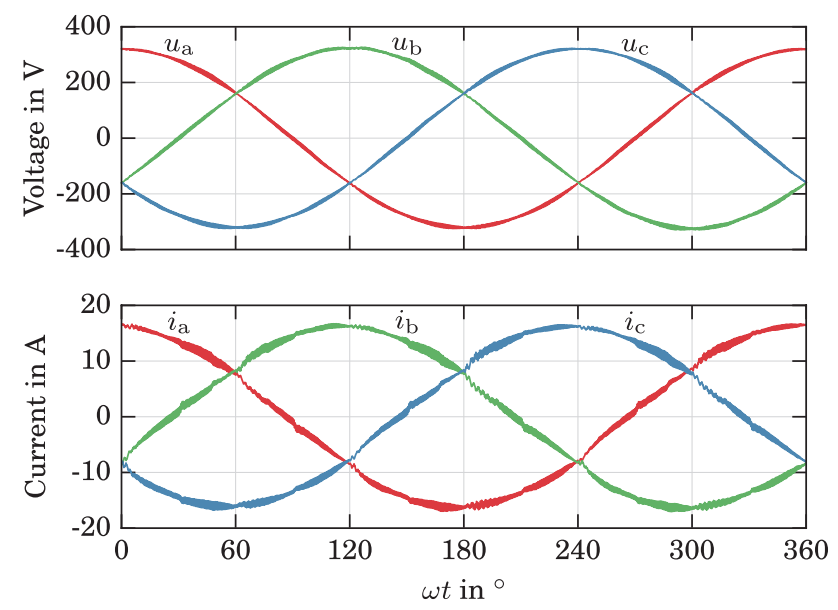

Fig. 19. Measurement results with the converter operating at nominal conditions and full output power, i.e. $P=8 \mathrm{~kW}, U_{1}=230 \mathrm{~V}_{\mathrm{rms}}$ and $U_{\mathrm{pn}}=400$ $\mathrm{V}$. Note that phase quantities a and $\mathrm{c}$ were measured directly, phase $\mathrm{b}$ was recreated numerically as $u_{\mathrm{b}}=-\boldsymbol{u}_{\mathrm{a}}-\boldsymbol{u}_{\mathrm{c}}$ and $i_{\mathrm{b}}=-i_{\mathrm{a}}-i_{\mathrm{c}}$.

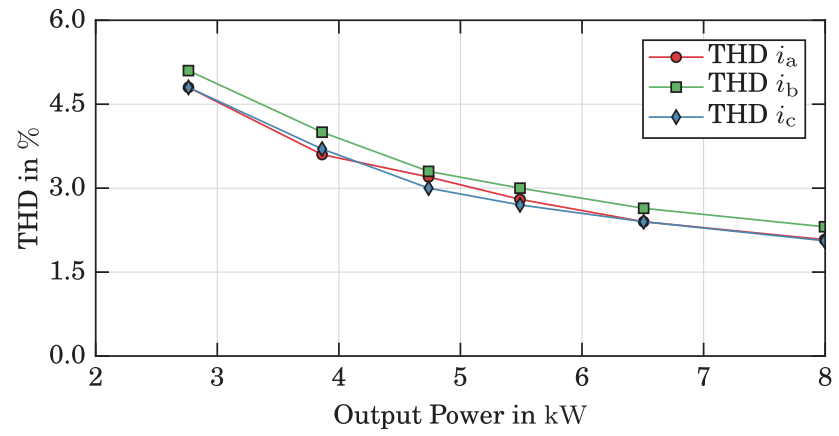

Fig. 20. Total harmonic distortion (THD) values of the rectifier's mains input line currents as a function of output power for nominal input and output voltages, measured using a Yokogawa WT 3000 power analyzer. 
tion. The measured total harmonic distortion of the mains input currents as a function of the dc output power is shown in Fig. 20.

\section{B. Efficiency}

A comparison of the rectifier's calculated and measured efficiency as a function of dc output power is shown in Fig. 21. The solid lines show the calculated efficiency for $400 \mathrm{~V}$ and $380 \mathrm{~V}$ output voltage, while the round and triangular markers show measurements taken with a Yokogawa WT 3000 power analyzer. Additionally three efficiency measurements were taken based on a direct measurement of the converter's losses using a calorimeter which closely match the values obtained by the electrical measurement.

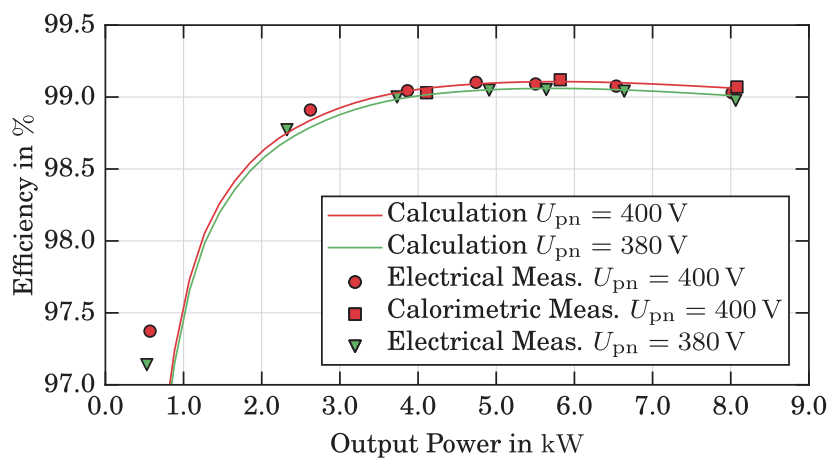

Fig. 21. Comparison of measured and calculated converter efficiencies for two different dc output voltages $U_{\mathrm{pn}}$. The electrical efficiency measurements were performed with a Yokogawa WT 3000 power analyzer. For $U_{\mathrm{pn}}=400 \mathrm{~V}$ additional measurements were done using a calorimeter. All measurements were taken at nominal ac input voltage $U_{1}=230 \mathrm{~V}_{\mathrm{rms}}$ and an ambient temperature of 30 degrees $\mathrm{C}$.

\section{ICT Current Balance}

As written in Section II-C unsymmetries in the interleaved
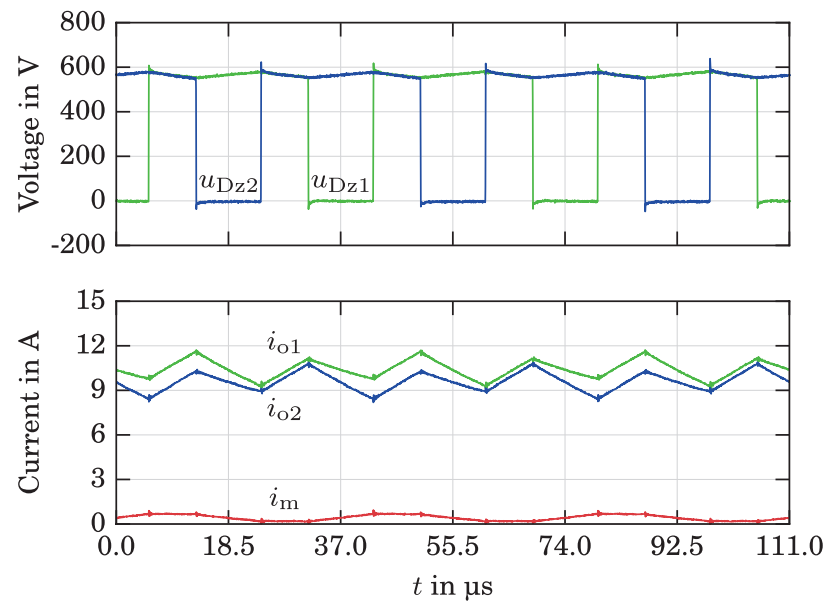

Fig. 22. Measurement of the interleaved buck converter output voltages $u_{\mathrm{Dz} 1}$ and $u_{\mathrm{D} 22}$, the ICT currents $i_{\mathrm{o} 1}$ and $i_{\mathrm{o} 2}$ and the calculated ICT magnetizing current $i_{\mathrm{m}}$ for converter operation with nominal power at $\omega t \approx 0^{\circ}$, i.e. at the peak of the six-pulse voltage $u_{\mathrm{xz}}$ (cf. Fig. 3 ) with a peak value of $i_{\mathrm{m}, \max }=0.73 \mathrm{~A}$. buck converter lead to an unbalance of the ICT currents $i_{\mathrm{o} 1}$ and $i_{\mathrm{o} 2}$ which create a dc offset in the ICT's magnetizing current $i_{\mathrm{m}}$. Measurement results of the buck converter output voltages $u_{\mathrm{Dz} 1}, u_{\mathrm{D} 22}$, the ICT currents and the derived magnetizing current are shown in Fig. 22. Note that no active controller was used to balance $i_{01}$ and $i_{02}$, resulting in a peak magnetizing current of $0.73 \mathrm{~A}$ and average value of $0.42 \mathrm{~A}$. This corresponds to a peak core flux density of $\approx 460 \mathrm{mT}$ which is far below the core material's saturation flux density of $1.2 \mathrm{~T}$.

\section{Conducted EMI}

A two stage EMI filter with a reactive power consumption of $\approx 4 \%$ of the rectifiers output power rating has been implemented. Its structure is shown in Fig. 23 and the values of all components are listed in Table III. However, a detailed analysis of the filter and of its design process is out of the scope

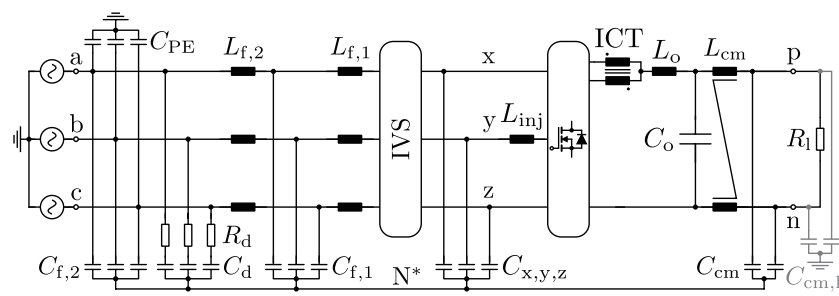

Fig. 23. Schematic of the implemented EMI filter with two combined CM/ DM filter stages $L_{\mathrm{f}, 1}, C_{\mathrm{f}, 1}$ and $L_{\mathrm{f}, 2}, C_{\mathrm{f}, 2}$ at the ac input and an additional CM filter stage $L_{\mathrm{cm}}, C_{\mathrm{cm}}$ at the dc output. The component values used in the prorotype are listed in Table III.

TABLE III

EMI FiLTER COMPONENTS

\begin{tabular}{ccl}
\hline \hline$C_{\mathrm{xyz}}$ & $4.4 \mu \mathrm{F}$ & $2 \times 2.2 \mu \mathrm{F}$ Epcos B32923, X2 in parallel \\
$L_{\mathrm{f}, 1}$ & $22 \mu \mathrm{H}$ & PQ26/25, 10 turns, 1 x 4mm wire \\
$C_{\mathrm{f}, 1}$ & $2.3 \mu \mathrm{F}$ & $5 \times 470 \mathrm{nF}$ Epcos B32922, X2 in parallel \\
$L_{\mathrm{f}, 2}$ & $15 \mu \mathrm{H}$ & Würth Elektronik 7443641500 \\
$C_{\mathrm{f}, 2}$ & $1.4 \mu \mathrm{F}$ & $3 \times 470 \mathrm{nF}$ Epcos B32922, X2 in parallel \\
$C_{\mathrm{d}}$ & $0.9 \mu \mathrm{F}$ & $2 \times 470 \mathrm{nF}$ Epcos B32922, X2 in parallel \\
$R_{\mathrm{d}}$ & $4.7 \Omega$ & $4 \times 1 \mathrm{~W} 1218 \mathrm{SMD}$ Thick Film resistors \\
$C_{\mathrm{PE}}$ & $47 \mathrm{nF}$ & Epcos B3202, Y2, connected to case \\
$L_{\mathrm{cm}}$ & $\approx 200 \mu \mathrm{H}$ & Vacuumschmelze W424, 5 turns, 2.5mm wire \\
$C_{\mathrm{cm}}$ & $130 \mathrm{nF}$ & $4 \times 33 \mathrm{nF}$ MLCC in parallel \\
\hline \hline
\end{tabular}

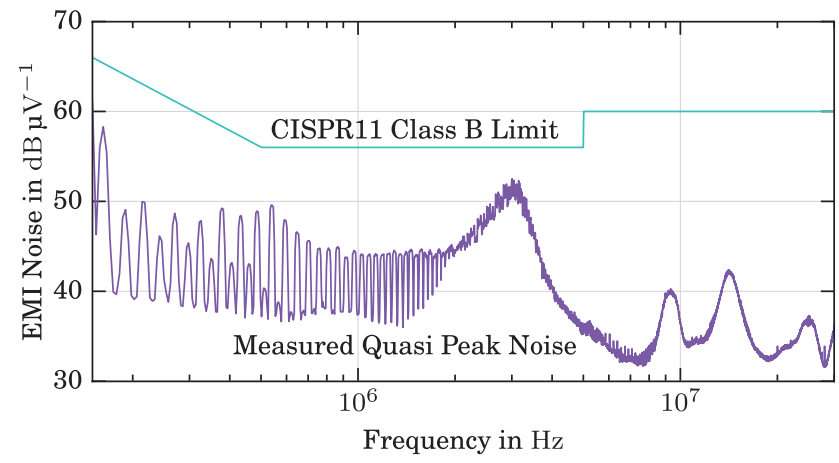

Fig. 24. Measured quasi-peak conducted EMI noise emission and corresponding CISPR11 class B limit for the $150 \mathrm{kHz}$ to $30 \mathrm{MHz}$ range with a bandwith of $9 \mathrm{kHz}$, measured in $4 \mathrm{kHz}$ steps. 
of this paper. Measurement results of the conducted EMI noise spectrum, using the quasi-peak detector, are shown in Fig. 24 together with the CISPR11 class B limit for the 150 $\mathrm{kHz}$ to $30 \mathrm{MHz}$ range.

\section{Conclusion}

This paper describes a life cycle cost driven optimization process were not only the first cost of a converter, but also the capital equivalent worth of the energy dissipated during the system's service life is considered. This allows the selection of optimal components, such as switches, inductors, transformers, etc., which achieve minimal cost for a given application, run time and switching frequency. By sweeping over a range of suitable switching frequencies a cost optimal converter system can then be found.

As an example an $8 \mathrm{~kW}$ buck-type three-phase interleaved Integrated Active Filter rectifier for $380 \mathrm{~V}$ dc distribution systems in data center and telecommunication applications is designed. Using state-of-the-art SiC MOSFETs and nanocrystalline cores a design with a power density of $4 \mathrm{kWdm}^{-3}$ and an efficiency of $99 \%$ results. Measurement results taken on a hardware prototype verify the validity of the employed models.

However, the cost driven optimization process is not only useful for data center applications with continuous operation, but could also be used in other applications were the system operates only for a relatively short period of time. For example in an on-board charger of a plug-in hybrid vehicle, which is used only once or twice a day for 1 to 2 hours, the first cost. Similarly the cost of weight and volume is expected to have significant impact on power electronic systems in aircraft, where weight has an impact on the vehicle's fuel consumption and hence on the life cycle cost. This is expected to lead to cost optimal systems with a higher switching frequency, higher power density and lower efficiency. In such cases an equivalent first cost, including weight and/or volume and the cost of conversion losses can still be used to compare, optimize and select components, circuit topologies and converter systems achieving minimal life cycle cost.

\section{ACKNOWLEDGMENT}

The authors would like to thank ABB Switzerland Ltd. for the funding and for their support regarding many aspects of this research project. Furthermore we would like to thank Ms. A. Kengunte for her help in the design, assembling and commissioning of the hardware prototype.

\section{REFERENCES}

[1] R. Hintemann, and K. Fichter, "Energy consumption and quantities of materials in german data centers," in Proc. of Electronics Goes Green $(E G G)$, Sept. 2012, pp. 1-6.

[2] R. Brown, E. Masanet, B. Nordman, W. Tschudi, A. Shehabi, J. Stanley, J. Koomey, D. Sartor, P. Chan, J. Loper, S. Capana, B. Hedman, R. Duff, E. Haines, D. Sass, and A. Fanara, "Report to congress on server and data center energy efficiency: Public law 109-431, LBNL-363E," Lawrence Berkeley National Laboratory, Berkeley,
California, Tech. Rep., 2007.

[3] A. Shehabi, S. Smith, D. Sartor, R. Brown, M. Herrlin, J. Koomey, E. Masanet, N. Horner, I. Azevedo, and W. Lintner, "United States data center energy usage report, "Lawrence Berkeley National Laboratory, Berkeley, California, Tech. Rep. LBNL-1005775, 2016.

[4] A. Pratt, P. Kumar, and T. V. Aldridge, "Evaluation of 400V DC distribution in Telco and data centers to improve energy efficiency," in Proc. of International Telecommunications Energy Conference (INTELEC), Sept. 2007, pp. 32-39.

[5] G. AlLee, and W. Tschudi, "Edison Redux: 380 Vdc brings reliability and efficiency to sustainable data centers," IEEE Power and Energy Magazine, vol. 10, no. 6, pp. 50-59, Nov. 2012.

[6] D. E. Geary, D. P. Mohr, D. Owen, M. Salato, and B. J. Sonnenberg, "380V DC eco-system development: Present status and future challenges," in Proc. of International Telecommunications Energy Conference (INTELEC), Oct. 2013, pp. 1-6.

[7] ETSI, "Environmental Engineering (EE); Power supply interface at the input to telecommunications and datacom (ICT) equipment; Part 3: Operated by rectified current source, alternating current source or direct current source up to $400 \mathrm{~V}$; Sub-part 1: Direct current source up to 400V," EN 300 132-3-1, Feb. 2012.

[8] T. Soeiro, T. Friedli, and J. W. Kolar, "Three-Phase High Power Factor Mains Interface Concepts for Electric Vehicle Battery Charging Systems," in Proc. of Applied Power Electronics Conference and Exposition (APEC), Feb. 2012, pp. 2603-2610.

[9] T. B. Soeiro, F. Vancu, and J. W. Kolar, "Hybrid active third-harmonic current injection mains interface concept for DC distribution systems," IEEE Transactions on Power Electronics, vol. 28, no. 1, pp. 7-13, Jan. 2013.

[10] J. W. Kolar, and T. Friedli, "The essence of three-phase PFC rectifier systems - Part I," IEEE Transactions on Power Electronics, vol. 28, no. 1, pp. 176-198, Jan. 2013.

[11] B. Guo, F. Wang, and E. Aeloiza, "A novel three-Phase current source rectifier with delta-type input connection to reduce the device conduction loss," IEEE Transactions on Power Electronics, vol. 31, no. 2, pp. 1074-1084, Feb. 2016.

[12] S. Zhao, J. M. Molina, M. Silva, J. A. Oliver, P. Alou, J. Torres, F. Arévalo, O. García, and J. A. Cobos, "Design of energy control method for three-phase buck-type rectifier with very demanding load steps to achieve smooth input currents," IEEE Transactions on Power Electronics, vol. 31, no. 4, pp. 3217-3226, Apr. 2016.

[13] M. Jantsch, and C. W. G. Verhoeve, "Inverters with three-phase output and without electrolyte capacitor for improved lifetime, efficiency and costs of grid connected systems," in Proc. of 14th European Photovoltaic Solar Energy Conference, Jun. 1997.

[14] H. Yoo, and S. Sul, "A novel approach to reduce line harmonic current for a three-phase diode rectifier-fed electrolytic capacitorless inverter," in Proc. of Applied Power Electronics Conference and Exposition (APEC), Feb. 2009, pp. 1897-1903.

[15] L. Schrittwieser, J. W. Kolar, and T. B. Soeiro, " $99 \%$ efficient threephase buck-type SiC MOSFET PFC rectifier minimizing life cycle cost in DC data centers," in Proc. of IEEE International Telecommunications Energy Conference (INTELEC), Oct. 2016, pp. 1-8.

[16] "Novel SWISS rectifier modulation scheme preventing input current distortions at sector boundaries," IEEE Transactions on Power Electronics, 2016, to be published.

[17] M. Hirakawa, Y. Watanabe, M. Nagano, K. Andoh, S. Nakatomi, S. Hashino, and T. Shimizu, "High power DC/DC converter using extreme close-coupled inductors aimed for electric vehicles," in Proc. of International Power Electronics Conference (IPEC), Jun. 2010, pp. 2941-2948.

[18] F. Forest, E. Labouré, T. A. Meynard, and V. Smet, "Design and comparison of inductors and intercell transformers for filtering of PWM inverter output," IEEE Transactions on Power Electronics, vol. 24, no. 3, pp. 812-821, Mar. 2009.

[19] B. Cougo, T. Friedli, D. O. Boillat, and J. W. Kolar, "Comparative evaluation of individual and coupled inductor arrangements for input filters of PV inverter systems," in Proc. of International Conference on Integrated Power Electronics Systems (CIPS), Mar. 2012, pp. 1-8.

[20] S. Utz, and J. Pforr, "Current-balancing controller requirements of automotive multi-phase converters with coupled inductors," in Proc. 
of Energy Conversion Congress and Exposition (ECCE), Sep. 2012, pp. 372-379.

[21] D. O. Boillat, and J. W. Kolar, "Modeling and experimental analysis of a coupling inductor employed in a high performance AC power source," in Proc. of Renewable Energy Research and Applications (ICRERA), Nov. 2012, pp. 1-18.

[22] M. E. Jacobs, "Worth of a watt: The new economics and technologies," in Proc. of International Telecommunications Energy Conference (INTELEC), Sept. 2008, pp. 1-7.

[23] R. M. Burkart, and J. W. Kolar, "Comparative life cycle cost analysis of si and SiC PV converter systems based on advanced $\eta-\rho-\sigma$ multiobjective optimization techniques," IEEE Transactions on Power Electronics, vol. 32, no. 6, pp. 4344-4358, Jun. 2017.

[24] A. Stupar, T. Friedli, J. Miniböck, and J. W. Kolar, "Towards a 99\% efficient three-phase buck-type PFC rectifier for 400-V DC distribution systems," IEEE Transactions on Power Electronics, vol. 27, no. 4, pp. 1732-1744, Apr. 2012.

[25] F. Xu, B. Guo, L. M. Tolbert, F. Wang, and B. J. Blalock, "An all$\mathrm{SiC}$ three-phase buck rectifier for high-efficiency data center power supplies," IEEE Transactions on Industry Applications, vol. 49, no. 6, pp. 2662-2673, Nov. 2013.

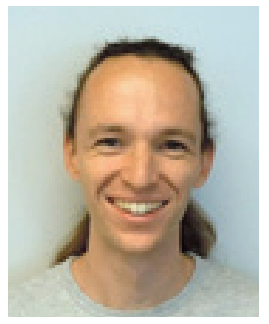

Lukas Schrittwieser received the M.Sc. degree in electrical engineering from the Swiss Federal Institute of Technology (ETH Zurich), Zurich, Switzerland, in 2014. He is currently working toward the Ph.D. degree at the Power Electronic Systems Laboratory, ETH, focusing on efficient three-phase buck-type PWM rectifiers for data centers, battery charging and dc distribution systems. His research interests include efficient converter systems, applications of wide bandgap semiconductor devices and measurement technologies.

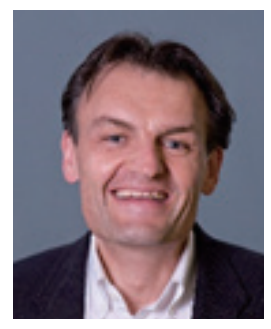

Johann W. Kolar is a Fellow of the IEEE and has received his M.Sc. degree in Industrial Electronics and Control Engineering and his Ph.D. degree in Electrical Engineering (summa cum laude) from the Vienna University of Technology, Austria. Since 1984 he has been working as an independent researcher and international consultant in close collaboration with the Vienna University of Technology, in the fields of power electronics, industrial electronics and high performance drives. He was appointed Assoc. Professor and Head of the Power Electronic Systems Laboratory at the Swiss Federal Institute of Technology (ETH) Zurich on Feb. 1, 2001, and was promoted to the rank of Full Prof. in 2004. He has proposed numerous novel PWM converter topologies (e.g. the VIENNA Rectifier, Sparse Matrix Converter, and SWISS Rectifier), and modulation and control concepts and has supervised over $60 \mathrm{Ph}$.D. students. He has published over 750 scientific papers in international journals and conference proceedings, 3 book chapters, and has filed more than 140 patents. He has presented over 20 educational seminars at leading international conferences, has served as IEEE PELS Distinguished Lecturer from 2012 through 2016, and has received 25 IEEE Transactions and Conference Prize Paper Awards, the 2014 IEEE Power Electronics Society R. David Middlebrook Achievement Award, the 2014 SEMIKRON Innovation Award, the 2016 IEEE William E. Newell Power Electronics Award, the 2016 IEEE PEMC Council Award, and the ETH Zurich Golden Owl Award for excellence in teaching. He has initiated and/or is the founder of 4 ETH Spin-off companies. The focus of his current research is on ultra-compact and ultra-efficient $\mathrm{SiC}$ and $\mathrm{GaN}$ converter systems, wireless power transfer, Solid-State Transformers, Power Supplies on Chip, as well as ultra-high speed and ultra-light weight drives, bearingless motors, and energy harvesting.

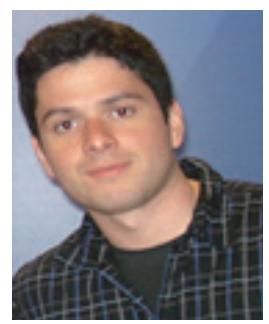

Thiago Batista Soeiro received the B.S. (Hons.) and M.S. degrees in electrical engineering from the Federal University of Santa Catarina, Florianopolis, Brazil, in 2004 and 2007, respectively, and the Ph.D. degree from the Swiss Federal Institute of Technology (ETH) Zurich, Zurich, Switzerland, in 2012.

During the Master and Ph.D. studies, he was a Visiting Scholar at the Power Electronics and Energy Research Group, Concordia University, Montreal, Canada, and at the Center for Power Electronics Systems, Blacksburg, USA, respectively. From 2012 to 2013, he was a Researcher at the Power Electronics Institute (INEP), Federal University of Santa Catarina (UFSC), Florianpolis, Brazil. He is currently with the Corporate Research of ABB Switzerland. He has received the "2013 IEEE IES Best Conference Paper Award", and the best paper awards in the following IEEE conferences: ECCE Asia 2011, ICIT 2013, and ECCE Europe 2015. His research interests include power factor correction techniques and advanced power converters. 